\title{
In vitro Evaluation of Antioxidant Activity of Picea smithiana Growing in Bhaderwah Region of Jammu and Kashmir
}

\author{
Bhagat $\mathbf{M}^{*}$, Gupta S and Sudan R \\ School of Biotechnology, University of Jammu, India
}

*Corresponding author: Madhulika Bhagat, School of Biotechnology, University of Jammu, Jammu, J\&K-180006, India, Email: madhulikabhagat@rediffmail.com

\section{Research Article}

Volume 2 Issue 1

Received Date: March 29, 2017

Published Date: May 04, 2017

\section{Abstract}

Picea smithiana is one of the plants belongs to family pinaceae that has not been explored scientifically from pharmaceutical point of view. The present study targeted to explore the antioxidant potential of Picea smithiana growing in Bhadewah region (Shoj dhar) at the altitude of 11000 feats of Jammu and Kashmir, India. Three types of extracts were prepared from leaf and Bark part of the plant viz. chloroform, methanol and aqueous and analyzed for their total phenols and flavonoid content. Antioxidant potential of the extracts were analyzed by four different method viz., DPPH radical scavenging method, $\mathrm{Fe}^{2+}$ ion chelating method, FRAP assay and Potassium ferric cyanide reduction method.

The results of the study determined that methanolic extract of leaf part contained good content of phenolic compound (70.4 $\pm 2.1 \mathrm{mg} \mathrm{GAE} / \mathrm{g} \mathrm{dw}$ ) which contributed as good antiradical ( $\mathrm{IC}_{50}$ value $228 \pm 3.2 \mu \mathrm{g} / \mathrm{ml}$ ), chelation activity ( $55 \pm 1.5 \%$ at $500 \mu \mathrm{g}$ ), FRAP ( $494 \pm 5.2 \mu \mathrm{mol} \mathrm{Fe}(\mathrm{II}) / \mathrm{g}$ ) and Potassium ferric cyanide reduction activity (EC 50 value of $978 \mu \mathrm{g} / \mathrm{ml}$ ). A correlation between the antioxidant activity (FRAP) and the phenolic content of Picea smithiana extracts has also been drawn and found significant $\left(\mathrm{R}^{2}=0.965\right)$. In comparison, bark extracts possess less poly phenols that confer poor antioxidant potential.

Keywords: Picea smithiana; Essential Oil; Antimicrobial Compounds; Bio autography

\section{Introduction}

The role of free radicals and reactive oxygen species has been recognized in pathogenesis of many human diseases like cardiovascular disease, cancer, diabetes, cataracts, aging and neurodegenerative diseases including alzheimer's disease, parkinson's disease, huntington's disease [1,2]. Free radicals can also cause deterioration of food by oxidation that constitutes a serious problem in food industries. However, antioxidants would be an option which prevent or delay auto oxidation either by inhibiting the formation of free radicals or by interrupting their proliferation. Some synthetic antioxidants such as
BHT and BHA are commercially available but these compounds are suspected to cause side effects [3].

This concern has resulted in an increased interest in the investigation of the effectiveness of naturally occurring compounds with antioxidant properties. Thus the natural antioxidants present in foods and other biological materials have attracted considerable interest because of their safety and potential nutritional and therapeutic effects. 


\section{Cell \& Cellular Life Sciences Journal}

Picea smithiana (Pinaceae) is an evergreen tree commonly called Morinda Spruce, usually found in the Himalayan range at an altitude of $2400-3600 \mathrm{~m}$. The plant also has some commercial application like timber, paper, and food additives. Its edible parts like, Young male and female cones used as a flavoring agent. Dried bark of this plant is used as a thickener in soups or added to cereals when making bread. Moreover, it's essential oil also being used in room spray, deodorants [4].

Essential oil Picea species are used in the treatment of catarrhal diseases of children by inhalation with hot water and for rheumatic and neuralgic [5]. Plants belonging to Pinaceae family, like Pinus roxburgii, Pinus wallichaina and Cedrus deodara have abundant commercial uses and have also been scientifically explored for various biological activities. However, limited scientific reports on Picea smithiana are available to support its biological activity and its active components. The present aims to explore the phytochemicals and antioxidant properties of different extracts of Picea smithiana.

\section{Material and Methods}

\section{Plant Material}

Plant material was collected in the month of August (2012), from meadows of Seoj dhar region (11000 fts) of Bhaderwah, Jammu and Kashmir. Identification of the plant was done by taxonomist of Department of Botany, University of Jammu, Jammu and a voucher specimen has been deposited in the herbarium of the department of botany, University of Jammu (Accession no: 14613).

\section{Preparation of Extracts}

Plant material (leaf and bark, separately) was shade dried and powdered in an electronic grinder. Three types of extracts were prepared in three different solvents viz., chloroform, methanol and water. $100 \mathrm{~g}$ of dried plant material was extracted in $500 \mathrm{ml}$ of solvent and the process was repeated thrice. Resulting extracts were pooled, filtered and the volume was reduced to $50 \mathrm{ml}$ using rotary vacuum evaporator and finally lyophilized to dried powder [6]. Percentage yield of the extracts of Picea smithiana was given in Table 1.

\begin{tabular}{|c|c|c|c|}
\hline $\begin{array}{c}\text { Extract of Picea } \\
\text { smithiana }\end{array}$ & \%age yield & $\begin{array}{c}\text { TPC (mg GAE/g dry } \\
\text { weight) }\end{array}$ & $\begin{array}{c}\text { TFC (mg QE/g dry } \\
\text { weight) }\end{array}$ \\
\hline Methanolic (Leaf) & 11.3 & $70.4 \pm 2.1$ & $16.2 \pm 0.7$ \\
\hline Aqueous (Leaf) & 8.4 & $57.5 \pm 1.8$ & $21.6 \pm 0.9$ \\
\hline Chloroform (Leaf) & 3.1 & $12 \pm 0.4$ & - \\
\hline Methanolic (Bark) & 12.4 & $40.6 \pm 1.9$ & $15.1 \pm 0.7$ \\
\hline Aqueous (Bark) & 9.3 & $14.5 \pm 0.6$ & $26.3 \pm 1.2$ \\
\hline Chloroform (Bark) & 2.6 & - & - \\
\hline
\end{tabular}

Table 1: Percentage yield, total phenol and flavonoid content in Picea smithana extracts Experiment was conducted in triplicate and the values were given as mean \pm SD

\section{Total Phenols and Flavonoids in Extracts}

Total poly-phenol content in the extracts was determined by Folin-Ciocalteu method [7]. Briefly, $0.5 \mathrm{ml}$ of extract was mixed with $0.5 \mathrm{ml}$ of $1 \mathrm{~N}$ Folin-Ciocalteu reagent and $1 \mathrm{ml}$ of $20 \% \mathrm{Na}_{2} \mathrm{CO}_{3}$. After $10 \mathrm{~min}$ of incubation, the absorbance was measured at $750 \mathrm{~nm}$. The amount of total phenolic compounds was determined using a standard curve prepared from gallic acid (Make: Himedia) and expressed as milligram gallic acid equivalents per gram fresh weight (mg GAE/g) of sample.

Total flavonoid content of the extracts was determined by $\mathrm{AlCl}_{3}$ colorimetric method [8]. Plant extracts were diluted with distilled water to a volume of $3.5 \mathrm{ml}$ and added $150 \mu \mathrm{l}$ of a $5 \% \mathrm{NaNO}_{2}$ solution. After $5 \mathrm{~min}, 300 \mu \mathrm{l}$ of $10 \% \mathrm{AlCl}_{3}$ solution was added. After $6 \mathrm{~min}, 300 \mu \mathrm{l}$ of $1 \mathrm{M} \mathrm{NaOH}$ and $550 \mu \mathrm{l}$ of distilled water were added. The mixture was well shaken and absorbance was measured at $510 \mathrm{~nm}$ in UV-VIS spectrophotometer. The amount of total flavonoid content was determined using a standard curve prepared from Quercetin (Make: Sigma aldrich) and expressed as milligram Quercetin equivalents per gram fresh weight (mg QE/g) of sample.

\section{DPPH Radical Scavenging Activity}

Free radical scavenging activity of the extracts was determined by DPPH method given by Abe $\mathrm{N}$ et al. [9] with little modifications. A total of $1 \mathrm{ml}$ from a $0.5 \mathrm{~m}$ methanol solution of the DPPH radical was mixed to $2 \mathrm{ml}$ sample and to this $2 \mathrm{ml}$ of $0.1 \mathrm{M}$ sodium acetate buffer 


\section{Cell \& Cellular Life Sciences Journal}

(pH 5.5) was added. The mixtures were well shaken and kept at room temperature in the dark for $30 \mathrm{~min}$. The absorbance was measured at $517 \mathrm{~nm}$ using a UV-VIS spectrophotometer. BHT was used as reference antioxidant compound.

The radical scavenging activity (RSA) was calculated as a percentage of DPPH radical discoloration, using the equation:

$$
\% \mathrm{RSA}=\left[\left(\mathrm{A}_{0}-\mathrm{A}_{\mathrm{S}}\right) \mathrm{A}_{0}\right] \times 100
$$

Where, $A_{0}$ is the absorbance of the control and $A_{S}$ is the absorbance of the test compound.

\section{FRAP Assay}

The FRAP assay was carried out according to the method followed by Li HB et al. [10]. FRAP reagent was prepared in acetate buffer $(300 \mathrm{mM})$ by adding $10 \mathrm{mM}$ 2,4,6-tri (2-pyridyl)-s-triazine (TPTZ) solution in $40 \mathrm{mM}$ $\mathrm{HCl}$ and $20 \mathrm{mM} \mathrm{FeCl}_{3}$ solution in proportion of 10:1:1 $(\mathrm{v} / \mathrm{v})$, respectively. FRAP reagent was prepared fresh at the time of use. $50 \mu \mathrm{l}$ of the sample was added to $1.5 \mathrm{ml}$ of the FRAP reagent and after 3-4 min, absorbance was measured at $593 \mathrm{~nm}$. The standard curve was prepared by using $\mathrm{FeSO}_{4}(100-2000 \mu \mathrm{M})$ and the result was expressed as $\mu \mathrm{mol} \mathrm{Fe} \mathrm{(II)/gm} \mathrm{dry} \mathrm{weight} \mathrm{of} \mathrm{extract.} \mathrm{Gallic} \mathrm{acid} \mathrm{was}$ used as reference antioxidant compound.

\section{Chelation Activity}

The chelating potential of the Picea smithiana extracts on ferrous ions was estimated by the method given by Dinis TCP et al. [11]. Extract (0.5mg) in methanol was added to $20 \mu \mathrm{l}$ of $2 \mathrm{mM} \mathrm{FeCl}_{2}$. The reaction was initiated by the addition of $40 \mu \mathrm{l}$ of $5 \mathrm{mM}$ ferrozine into the mixture. The reaction mixture was incubated at room temperature for $10 \mathrm{~min}$ and finally the absorbance was measured at $562 \mathrm{~nm}$. EDTA was used as reference chelating agent. The ratio of inhibition of ferrozine-Fe ${ }^{2+}$ complex formation was calculated using the equation:

$$
\% \text { Inhibition }=\left[\left(\mathrm{I}_{0}-\mathrm{I}_{\mathrm{S}}\right) \mathrm{I}_{0}\right] \times 100
$$

Where, $\mathrm{I}_{0}$ is the absorbance of the control and $\mathrm{I}_{\mathrm{S}}$ is the absorbance of the test compound.

\section{Potassium Ferric Cyanide Reduction Method}

The reducing power of the samples was also assessed by potassium ferric cyanide reduction method with slight modifications [12]. Different dilutions of extracts/fractions were mixed with $2.5 \mathrm{~mL}$ of $0.2 \mathrm{M}$ phosphate buffer (pH 6.6). $2.5 \mathrm{~mL}$ of $1 \%$ potassium ferricyanide $\left(\mathrm{K}_{3} \mathrm{Fe}[\mathrm{CN}]_{6}\right)$ (Make: Himedia) was added and the mixture was incubated at $50{ }^{\circ} \mathrm{C}$ for $20 \mathrm{~min}$. After incubation, trichloroacetic acid was added to the mixture.

The mixture was then centrifuged at $1036 \times \mathrm{g}$ for 10 min. The upper layer of the solution $(2.5 \mathrm{~mL})$ was taken and mixed with $2.5 \mathrm{~mL}$ of distilled water. To this, $2.5 \mathrm{~mL}$ of $0.1 \%$ ferric chloride (Make: Himedia) solution was added and the absorbance was noted at $700 \mathrm{~nm}$. The extract concentration providing 0.5 of absorbance $\left(\mathrm{EC}_{50}\right)$ was calculated from the graph of absorbance at $700 \mathrm{~nm}$ against extract/fraction concentration.

\section{Results and Discussion}

The present study determined the antioxidant properties of different extracts of Picea smithiana leaf and bark. Three types of extracts were prepared viz., chloroform, methanol and aqueous, and their extractive yields has been depicted in Table 1. Maximum yield was observed in methanolic extracts of both the parts of Picea smithiana (leaf: $11.3 \%$ and bark: $12.4 \%$ ). Poor yield was observed in chloroform, in both parts of the plants. Antioxidant potential of Picea smithiana was analyzed by four methods viz., DPPH radical scavenging activity, and metal ion chelating activity, FRAP assay and reducing power.

The DPPH radical scavenging activity was determined on the basis of concentration providing 50\% effectiveness or radical scavenging activity $\left(\mathrm{EC}_{50}\right)$. Results of the study determined that methanol and aqueous extracts of leaf displayed highest antiradical efficiency with $\mathrm{EC}_{50}$ values $228 \pm 3.2 \mu \mathrm{g} / \mathrm{ml}$ and $331 \pm 4.1 \mu \mathrm{g} / \mathrm{ml}$, respectively Table 2 . In comparison bark methanol extract showed poor radical scavenging activity with $\mathrm{EC}_{50}$ values $457.3 \pm 5.2 \mu \mathrm{g} / \mathrm{ml}$. Aqueous and chloroform extracts of bark have shown negligible radical scavenging activity. BHT as standard showed effective radical scavenging activity with $\mathrm{EC}_{50}$ value $23.5 \pm 0.5 \mu \mathrm{g} / \mathrm{ml}$. 


\section{Cell \& Cellular Life Sciences Journal}

\begin{tabular}{|c|c|c|c|c|}
\hline Extract of Picea smithiana & $\begin{array}{c}\text { DPPH Assay (EC } \\
\text { in } \boldsymbol{\mu g} / \mathbf{m l})\end{array}$ & $\begin{array}{c}\text { FRAP Assay ( } \mathbf{m m o l} \\
\text { FeII /g) }\end{array}$ & $\begin{array}{c}\text { Reducing power } \\
\text { (EC } \mathbf{5 0} \text { in } \boldsymbol{\mu g} / \mathbf{m l})\end{array}$ & \%age Chelation \\
\hline Methanolic (Leaf) & $228 \pm 3.2$ & $494 \pm 5.2$ & $978 \pm 8.1$ & $55 \pm 1.5$ \\
\hline Aqueous (Leaf) & $331 \pm 4.1$ & $423 \pm 8.3$ & $1235 \pm 11.1$ & $14 \pm 0.6$ \\
\hline Chloroform (Leaf) & - & $157 \pm 5.1$ & $4832 \pm 14.4$ & $16 \pm 0.4$ \\
\hline Methanolic (Bark) & $457 \pm 8.6$ & $250 \pm 6.3$ & $1653 \pm 15$ & $49 \pm 1.8$ \\
\hline Aqueous (Bark) & - & $185 \pm 4.3$ & $1652 \pm 14.2$ & $37 \pm 1.4$ \\
\hline Chloroform (Bark) & - & - & $4947 \pm 17.2$ & $30 \pm 0.9$ \\
\hline BHT & $23.5 \pm 0.5$ & - & - & - \\
\hline Gallic acid & - & $19320 \pm 51.2$ & $150 \pm 4$ & - \\
\hline EDTA & - & - & - & $98 \pm 1.8$ \\
\hline
\end{tabular}

Table 2: Free radical scavenging, reducing and metal ion chelating activity of Picea smithiana extracts.

Experiment was conducted in triplicate and the values were given as mean \pm SD.

Chelation of metal ions is one of important mechanism of antioxidant activity. Metal ion chelation capacity was determined at $0.5 \mathrm{mg} / \mathrm{ml}$ concentration. Again, methanol leaf extract of Picea smithiana showed a better chelating effect on ferrous ions $(55 \pm 1.5 \%)$ than all the leaf and bark extracts. Methanol bark extract also showed good chelating capacity with $49 \pm 1.8 \%$ at $0.5 \mathrm{mg} / \mathrm{ml}$. Aqueous and chloroform extracts of leaf part showed poor chelating activity. EDTA, used as positive reference showed $98 \pm 1.8 \%$ chelating activity at the given concentration Table 2 .

FRAP is the ability of antioxidants to reduce $\mathrm{Fe}^{3+}$ to $\mathrm{Fe}^{2+}$ in the presence of TPTZ, forming an intense blue $\left(\mathrm{Fe}^{2+}\right.$ TPTZ complex) [10]. The results of reducing power were expressed in $\mu \mathrm{mol} \mathrm{Fe}$ (II)/g dry weight as given in Table 2 . Strongest antioxidant activity to reduce the Ferric ions $\left(\mathrm{Fe}^{3+}\right)$ was observed in leaf methanol extract of Picea smithiana (494 $\pm 5.2 \mu \mathrm{mol} \mathrm{Fe}$ (II)/g) followed by its aqueous extract ( $423 \pm 8.3 \mu \mathrm{mol} \mathrm{Fe}$ (II)/g) similar to the radical scavenging activity. Bark of Picea smithiana showed moderate reducing activity in methanol and aqueous extracts $(250 \pm 6.3 \mu \mathrm{mol}$ and $185 \pm 4.3 \mu \mathrm{mol} \mathrm{Fe}$ (II)/g respectively). Gallic acid was used as a standard reducing agent that determined extremely high reducing activity (19320 $\pm 51.2 \mu \mathrm{mol} \mathrm{Fe}$ (II)/g).

Reducing potential of the extracts was also analyzed by potassium ferric cyanide reduction method. Presence of reducing components in the test sample results into reduction of $\mathrm{Fe}^{3+} /$ Ferric cyanide complex. Different concentrations of the test samples were tested and the results were expressed as $\mathrm{EC}_{50}$ Table 2. Analysis showed that methanol extracts of leaf part of Picea smithiana displayed better reducing power with $\mathrm{EC}_{50}$ value of 978 $\mu \mathrm{g} / \mathrm{ml}$. Methanol and aqueous extracts of bark showed low reducing activity with $\mathrm{EC}_{50}$ value of $1653 \mu \mathrm{g} / \mathrm{ml}$ and $1652 \mu \mathrm{g} / \mathrm{ml}$ respectively.

Phenolic compounds have already been known to possess various biological activities like, antioxidant, antimicrobial etc. Table 1 represented total phenol and total flavonoid content in leaf and bark extracts of Picea smithiana. Highest amount of poly phenols was observed in methanol extract of leaf $70.4 \pm 2.1 \mathrm{mg}$ GAE/g dry weight) followed by aqueous extract of leaf ( $57.5 \pm 1.8 \mathrm{mg}$ GAE/g dry weight). Bark extracts possess comparatively less phenolic content whereas, least amount was observed in chloroform extracts of both leaf and bark. Aqueous extracts of both leaf and bark contained relatively higher amount of flavonoids $(21.6 \pm 0.9 \mathrm{mg}$ QE/g and $26.3 \pm 1.2 \mathrm{mg} \mathrm{QE} / \mathrm{g}$ dry weight, respectively) than methanol extracts of leaf and bark $(16.2 \pm 0.7 \mathrm{mg}$ $\mathrm{QE} / \mathrm{g}$ and $15.1 \pm 0.7 \mathrm{mg} \mathrm{QE} / \mathrm{g}$ dry weight, respectively). Like total phenolics, chloroform extracts of Picea smithiana contained trace amount of flavonoids. Many studies have shown that the antioxidant activities in the plants are associated with their phenolic contents. This may be due to their redox properties of the phenolic compounds that make them good reducing, scavenging and chelating agent [7-14] investigated the phytochemicals and antioxidant activity of Pinus cembra L. bark and needles.

Their results determined that the bark extract had higher concentrations of total phenolics, flavonoids and 


\section{Cell \& Cellular Life Sciences Journal}

proanthocyanidins than needle extract. Bark extract also showed better radical scavenging activity with $\mathrm{EC}_{50}$ value of $71.1 \mu \mathrm{g} / \mathrm{mL}$ than needles [15] have reported the antioxidant activity of the essential oil of Picea smithiana growing in Kashmir (India). They observed moderate DPPH radical scavenging effect (35\%) of Picea smithiana essential oil at the given concentration of $100 \mu \mathrm{g} / \mathrm{ml}$, in comparison to standard $\alpha$-tocopherol $(100 \mu \mathrm{g} / \mathrm{ml})$ that showed $78 \%$ antiradical effect.

Antioxidant and phytochemical investigation of Pieca smithiana extracts revealed that there is significant correlation between the antioxidant activity and phenolic and flavonoid. Total phenolic content determined using Folin-Ciocateu method and reducing activity showed significant correlation $\left(R^{2}=0.965\right)$ between FRAP and the total phenolic content of Picea smithiana extracts. Similar correlation between total phenolic content and DPPH EC 50 values $\left(R^{2}=0.982\right)$ of the active extracts of Pieca smithiana has been observed. Therefore, it is possible that phenolic compounds are the major contributor for the antioxidant activity of the Picea smithiana.

\section{Conclusion}

The present study demonstrated the chemical composition and antioxidant potential of different extracts of Picea smithiana growing in Bhaderwah region of Jammu and Kashmir. The results conclude that methanol extract of Picea smithiana leaf contained good content of poly phenolic compound and that contributed as good radical scavenger and reductant as compare to other extracts.

\section{Conflict of Interest}

The authors have no conflict of interest regarding this paper.

\section{Acknowledgments}

Authors would like to acknowledge the UGC-SAP, DSTFIST, PURSE, School of Biotechnology and Department of Bio-informatics, University of Jammu, for their support. The authors also wish to acknowledge Dr. Harish Dutt (Taxonomist, Department of Botany in University of Jammu) for his guidance.

\section{References}

1. Lu JM, Lin PH, Yao Q, Chen C (2010) Chemical and molecular mechanisms of antioxidants: experimental approaches and model systems. Journal of cellular and molecular medicine 14(4): 840-860.

2. Melo A, Monteiro L, Lima RM, De Oliveira, El-Bacha RS, et al. (2011) Oxidative stress in neurodegenerative diseases: mechanisms and therapeutic perspectives. Oxidative medicine and cellular longevity.

3. Ito N, Fukushima S, Haqlwara A, Shibata M, Ogiso T (1983) Carcinogenicity of butylated hydroxyanisole in F344 rats. Journal of the National Cancer Institute 70(2): 343-352.

4. Conifer Specialist Group IUCN Red List of Threatened species, IUCN (1998).

5. Pauli A, Schilcher H (2004) Specific Selection of Essential Oil Compounds for Treatment of Children's Infection Diseases. Pharmaceuticals 1: 1-30.

6. Thusoo S, Gupta S, Sudan R, Hussain R, Bhagat M, et al. (2014) Antioxidant Activity of Essential Oil and Extracts of Valeriana jatamansi Roots. Bio Med Research International, Article ID 614187.

7. Chang ST, Wu JH, Wang SY, Kang PL, Yang NS, et al. (2001) Antioxidant activity of extracts from Acacia confusa bark and heart wood. J Agric Food Chem 49: 3420-24.

8. Jia ZS, Tang MC, Wu JM (1999) The determination of flavonoid contents in mulberry and their scavenging effects on superoxide radicals. Food Chemistry 64: 555-559.

9. Abe N, Murata T, Hirota A (1998) Novel DPPH Radical Scavengers, Bisorbicillinol and Demethyltrichodimerol from a Fungus. Bioscience, Biotechnology and Biochemistry 62: 661-666.

10. Li HB, Wong CC, Cheng KW, Chen F (2008) Antioxidant properties in vitro and total phenolic contents in methanol extracts from medicinal plants. LWT- Food science and technology 41: 385-390.

11. Dinis TCP, Madeira VMC, Almeida, LM (1994) Action of phenolic derivatives (acetoaminophen, salicylate, and 5-aminosalicylate) as inhibitors of membrane ipid peroxidation and as peroxyl radical scavengers. Arch Biochem Biophys 315: 161-169.

12. Oyaizu M (1986) Studies on products of browning reaction antioxidative activities of products of 


\section{Cell \& Cellular Life Sciences Journal}

browning reaction prepared from glucosamine. Eiyogaku zasshi Japanese journal of nutrition.

13. Apetrei CL, Tuchilus C, Aprotosoaie AC, Oprea A, Malterud KE, et al. (2011) Chemical, antioxidant and antimicrobial investigations of Pinus cembra L. bark and needles. Molecules 16(9): 7773-7788.

14. Guleria S, Tiku AK, Singh G, Koul A, Gupta S et al. (2012) In vitro antioxidant activity and phenolic contents in methanol extracts from medicinal plants, J. Plant Biochem. Biotechnol 22: 9-15.
15. Shah WA, Dar MY (2014) Antiproliferative and antioxidant activity of Picea smithiana (Wall) Boiss oil. International Journal of Chemistry and Pharmaceutical sciences 2: 541. 